\title{
The Development of STEAM Teaching Model and Program based on Smart Device for Connection of Kindergarten-elementary School
}

\author{
*Rae-Eun Kim, Department of Social Welfare \& Counseling, U1 University, Yeongdong-Eup, Yeongdong-Gun, \\ 40002, Korea,versus486@u1.ac.kr \\ ${ }^{*}$ Corresponding Author
}

\begin{abstract}
The purpose of this study is to develop the STEAM teaching model and program based on smart device for connection of kindergarten-elementary school. We reviewed literature related to STEAM education and smart devices, developed the teaching model, and verified the validity of experts. This teaching model was applied for 15 weeks to 23 children aged 5-years and 45 children aged 7-years. After modifying and supplementing the application process analysis results, the STEAM teaching model based on smart device was finally developed. On the basis of the result of pilot testing, this teaching model was modified and finalized. The purpose of developing the STEAM teaching model based on smart device for young children aged 5 and 7-years was to increase their interest in and awareness of STEAM, creativity, and convergent thinking ability. As for the operation method, STEAM classes were planned and executed, plans were revised and re-executed according to the STEAM class standards for connection of kindergarten-elementary school. The purpose of developing the STEAM teaching model based on smart device for young children aged from 5-years to 7-years was to increase their interest in and awareness of STEAM, creativity, and convergent thinking ability. The STEAM teaching model based on smart device for connection of kindergarten-elementary school is 3 times of present situation, creative design and emotional experience for content convergent, and conclusion on problem solving. The STEAM program based on smart device for connection of kindergarten-elementary school developed a total of 8 activities. In the early stages of the application of smart device-based STEAM education, the development of a smart device-based STEAM class model can provide implications for connection of kindergarten-elementary school.
\end{abstract}

Keywords: young children, convergent education, STEAM program, STEAM teaching model, smart device, connection of kindergarten-elementary school

Received: 09.12.2020 Accepted: 13.01.2021 $\quad$ Published: 01.02.2021

\section{INTRODUCTION}

In the Republic of Korea, the direction of the education policy in 2016 is 'Education for everyone to be happy, creative talent who opens the future', and a creative convergence type of future talent education is being conducted, and STEAM has been introduced and applied as a national policy of Ministry of Education, Science and Technology in Korea [1]. Therefore, in the field of early childhood education, five areas of integrated education through the Nuri course for each age of 3 to 5 years are already being operated, and various STEAM programs for young children have been developed and applied recently in Korea $[2,3,4,5]$.

The 2015 elementary school curriculum and the 2019 revised Nuri curriculum emphasized the reinforcement of the linkage between the Nuri curriculum for each age group of 3 to 5 years old and the content of elementary school education, and argues that the application of STEAM education through linking the curriculum is necessary. Therefore, STEAM education should be conducted from early childhood to cultivate convergent talents, and development of STEAM programs for young children in connection with elementary school curriculum is also required for linkage education between kindergarten and elementary school. The curriculum currently applied in early childhood education is similar to STEAM education method because it applies integrated, topic-oriented, question-oriented, inquiry-oriented, practice-based learning, and constructivist education [6]. Likewise, despite the progress of STEAM-related research for young children, STEAM studies for early childhood teachers compared to elementary, middle, and high schools are incomplete.

In addition, there are several difficulties when applying steam programs in the field of early childhood education. In other words, in the field of early childhood education, there is no subject such as technology 
and engineering, and even in integrated education, the use of technology and engineering, which is the basic purpose of steam education, is remarkably insufficient. Therefore, when developing steam teaching models and programs for young children, it is necessary to use related teaching media in order to properly apply technology and engineering.

Recently, smart infrastructure technologies such as smart phones, tablet PCs, and smart TVs, and smart software technologies such as virtual reality and augmented reality, have rapidly developed '2020 Future of Education Report-Creation of Future Learning' according to the knowledge foundation in 2009 [1]. It is expected that traditional education will be destroyed due to changes in economy and society in 2020 . Therefore, there is a need for future STEAM education as an active learner who wants to actively understand and utilize technology in learners who accept passive skills. Despite the government's presentation of the 'Smart Education Policy' in 2010 and the application of various class models using smart devices to elementary school seniors, most smart devices have a user-friendly interface such as a touch screen. As a result, the age group of use is gradually decreasing.

In addition, the use of smart media in the field of early childhood education is universally applied, and despite the negative views or concerns when it was first introduced, it is effectively used in class and has a positive result [7]. Currently, the elementary school curriculum is already implementing smart education, and early childhood education institutions are also using a form that is familiar to young children through teaching media related to smart devices through the computer domain. In other words, the smart device is an effective learning medium that helps young children and elementary school students induce interest and focus attention and enables self-directed learning. According to a recent study, in order to use smart devices in early childhood education, systematic teacher education for the use of educational applications considering regional gaps and teacher age groups and development of early childhood education instructional models considering smart device addiction are necessary in the future [7].

Considering the previous studies of the STEAM program for young children applying the teaching media related to smart devices are as follows. [1] developed a smart device-based educational media model to improve children's steam education. That is, the teaching medium based on smart device for steam education is composed of animal synthesis drawing capable of interworking with smart device by wireless communication, lighting and temperature sensor capable of interlocking and controllable drawing of music invented by sound and sheet music, brightness and temperature and the ability to measure the size of the system. [8] developed the S-STEAM education program using machines for early childhood by reviewing previous studies and literature on science programs, science activities, 3-5 years old Nuri curriculum and S-STEAM education.

Nevertheless, since STEAM education and smart education, which are currently applied to the education field, are in a transitional period, they show a tendency to focus on the use of smart devices rather than applying smart devices as educational contents. In other words, teachers misunderstand the class using digital devices as if it were STEAM education, and teachers who are familiar with the traditional teaching methods show resistance to education using smart devices or complain of difficulties in how to apply digital devices to classes. As a result of analyzing the social perceptions of ICT utilization in early childhood education with big data analysis, it is found that the interest of smart, software application and robot in early childhood education field for the past three years has been high. Implications for the use of ICT media were discussed based on the results of the research [9]. [10] revealed that elementary school students who developed and applied the science and environment convergence human resources education (STEAM) program using smart devices were more effective in enhancing the formation of eco-friendly lifestyle habits of elementary school students than classes applying general theory classes.

Therefore, it is necessary to develop and apply early childhood education programs in which ICT such as smart devices are properly integrated, and teacher training related to ICT education programs must be systematically conducted. If the smart device-based STEAM program is developed and applied as a way to complement the areas where the distinction between technology and engineering is ambiguous due to the characteristics of elementary and elementary education, and activities related to technology and engineering are not diverse, desirable convergence education will be realized.

According to, this study developed a smart device-based STEAM teaching model as one of the methods to compensate for the fact that the distinction between technology and engineering is ambiguous due to the characteristics of early childhood education and elementary education, and activities related to technology and engineering are not diverse. I tried to develop the applied steam program. In other words, for effective preschool-elementary education, the direction of preschool STEAM education should go beyond the existing integrated education to become a convergence between science and technology based on smart devices that combine technology and engineering. There is a need to develop a smart devicebased STEAM program that seeks to develop creativity through experience. Due to the nature of early 
childhood education, it is necessary to develop a STEAM teaching model using a smart device as one of the ways to compensate for the blurring of technology and engineering and the lack of diverse activities related to technology and engineering.

The research questions set based on the theoretical background and research model of this study are as follows.

Question 1. What is the STEAM teaching model based on smart device for connection of kindergartenelementary school?

Question 2. What is the STEAM program based on smart device for connection of kindergartenelementary school?

\section{Materials and methods}

\subsection{Procedure}

Figure 1 shows the process for developing the STEAM teaching model and program applied that model based on smart device for connection of kindergarten-elementary school.

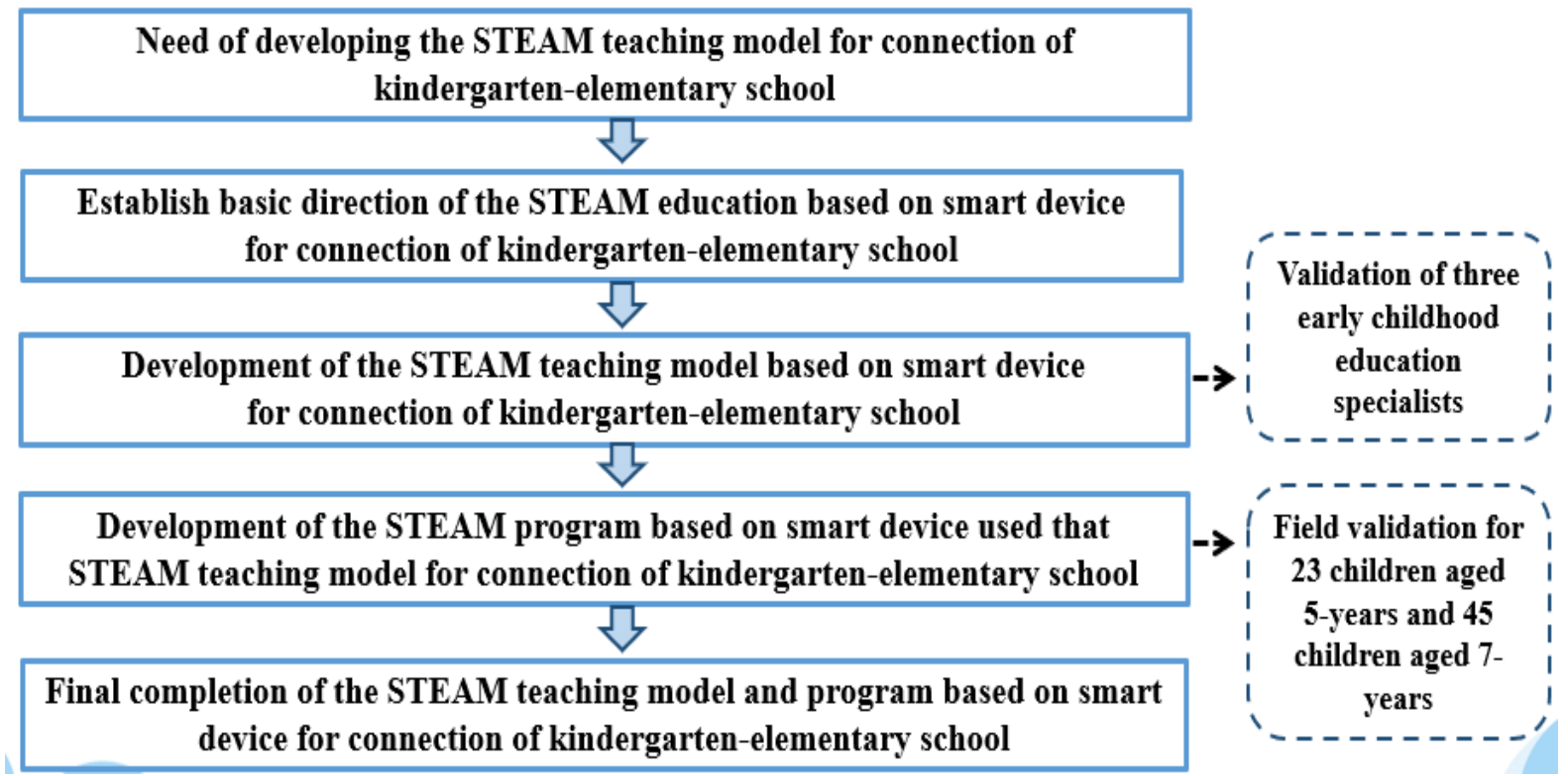

Figure 1 The process for developing the STEAM teaching model and program based on smart device for connection of kindergarten-elementary school

Figure 2 shows the process of development stage for the STEAM teaching model based on smart device

\section{[1: Preparation stage]}

\section{Review of literature}

Analyzing detailed elements of the STEAM class design framework and deriving common elements through literature review on smart device's utilization plan and activity standards of STEAM education

\section{Case analysis}

Analysis of application examples of the STEAM academic conference and performance presentation meeting of the Korea Science and Technology Foundation and the Ministry of Education to develop a smart device-based STEAM convergence model

[2: Development stage]

\section{Developing of STEAM teaching model and derivation of components}

After synthesizing the literature review and case analysis results, STEAM teaching model will be developed with reference to Cho(2013)'s STEAM integrated education model

\section{Validation by expert group}


for connection of kindergarten-elementary school.

Figure 2 The process of development stage for the STEAM teaching model based on smart device for connection of kindergarten-elementary school

\subsection{Smart device used on STEAM program}

Table 1 shows the sample of smart device used on the STEAM program based on STEAM teaching model.

Table 1 The sample of smart device used on the STEAM program
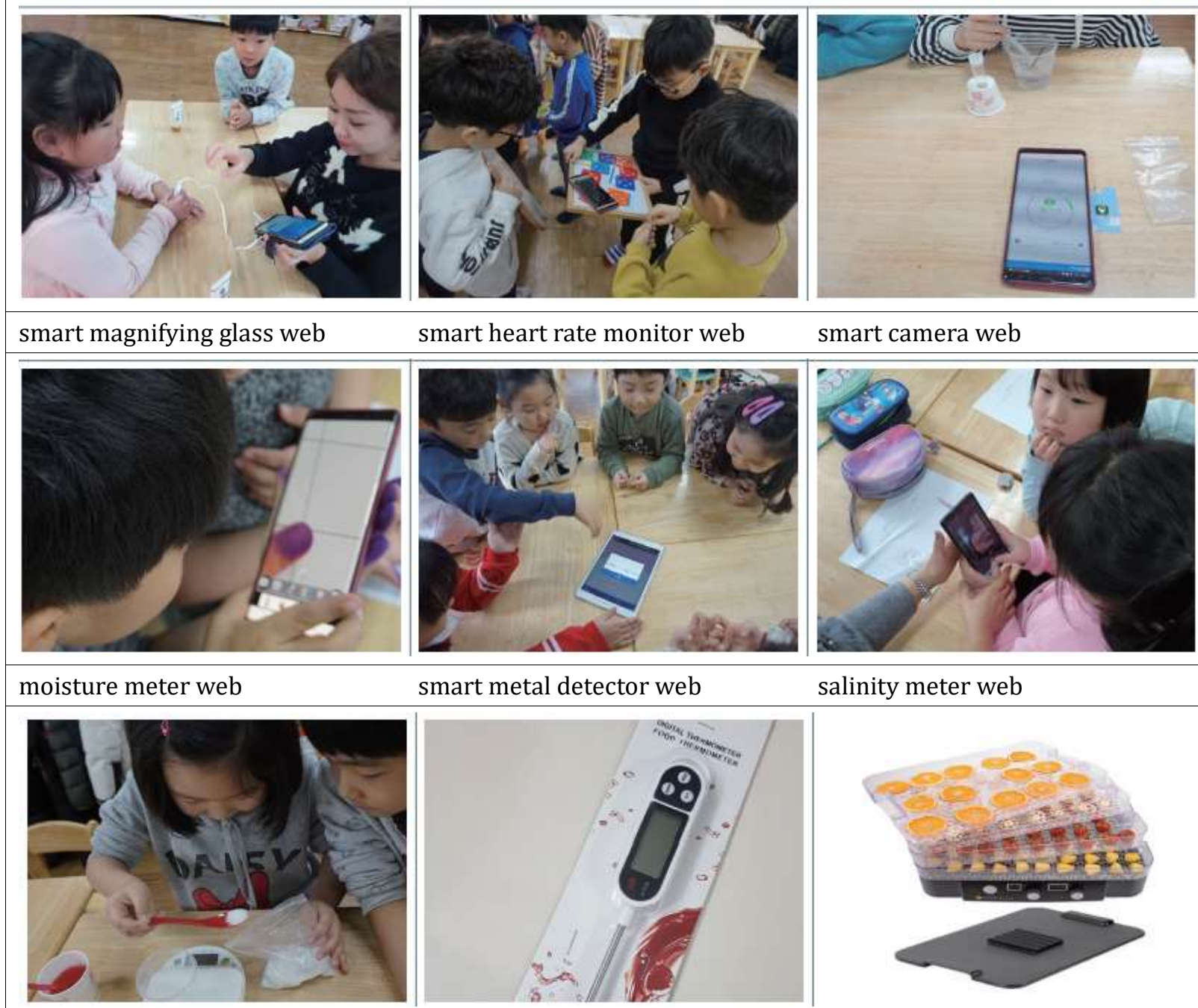

smart metal detector web

salinity meter web

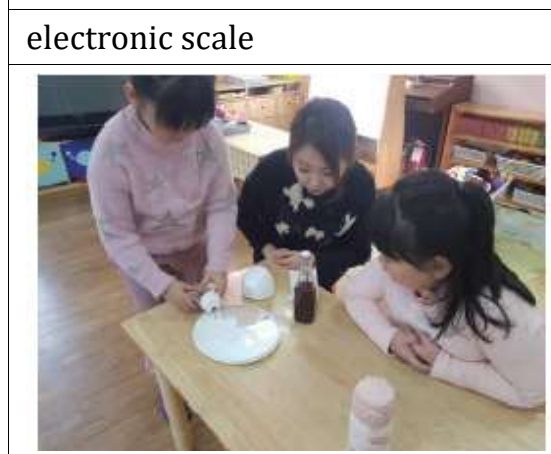

mask pack maker

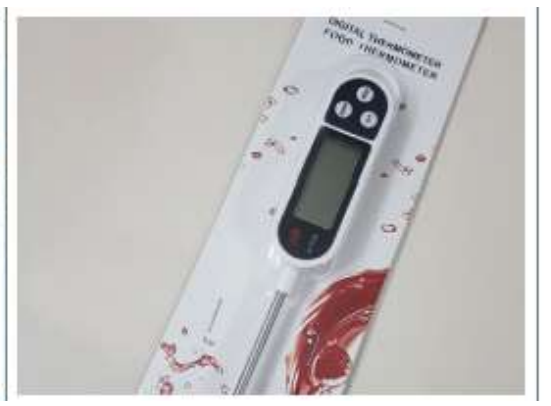

electronic thermometer
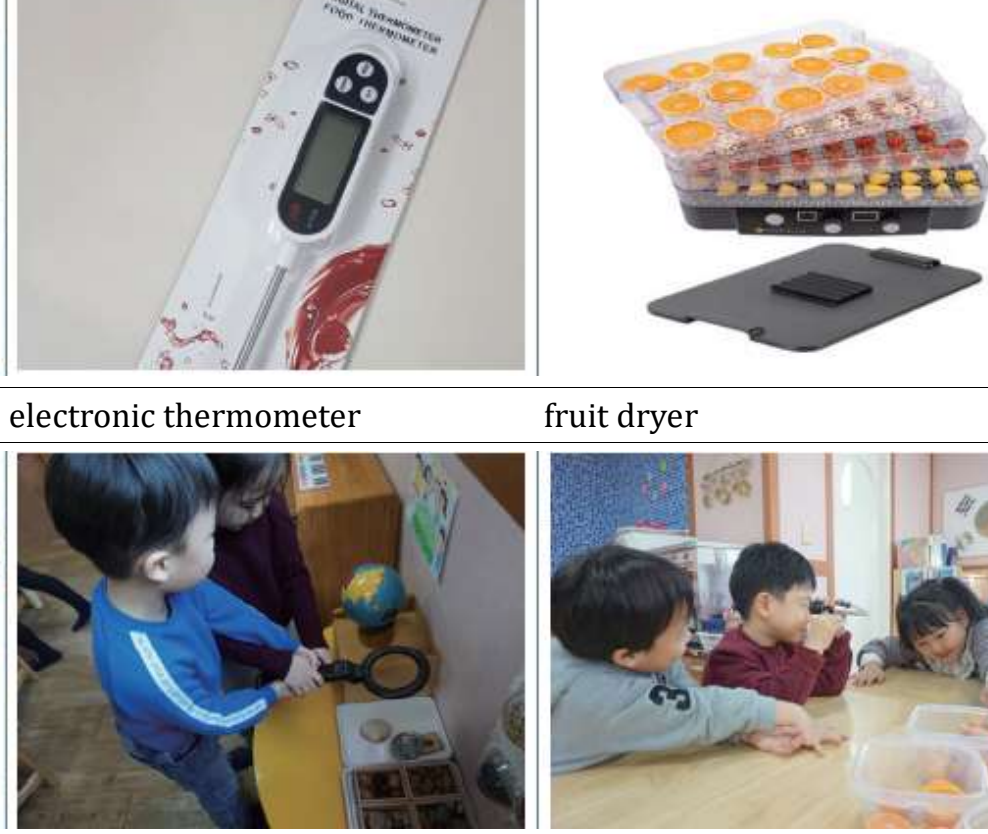

fruit dryer

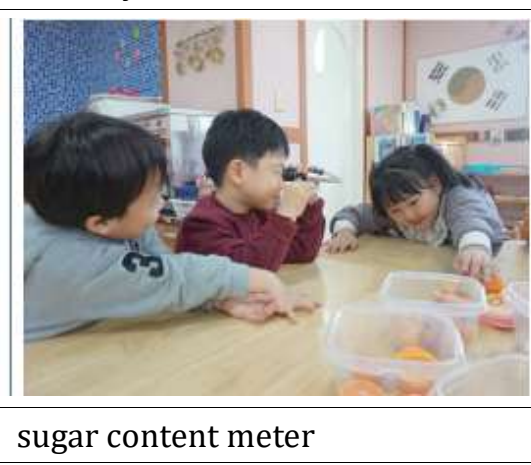

\section{Results}

3.1 The smart teaching model based on smart device

On the basis of the result of pilot testing, this teaching model was modified and finalized. The purpose 
of developing the STEAM teaching model based on smart device for young children aged from 5-years to 7-years was to increase their interest in and awareness of STEAM, creativity, and convergent thinking ability. The development principles and emphasis are on applying science-based convergence education that links other subjects, based on constructivist theory, and applying smart devices to emphasize technology and engineering. As for the operation method, STEAM classes were planned and executed, plans were revised and re-executed according to the STEAM class standards for young children.

Figure 3 shows the STEAM teaching model based on smart device for connection of kindergartenelementary school.

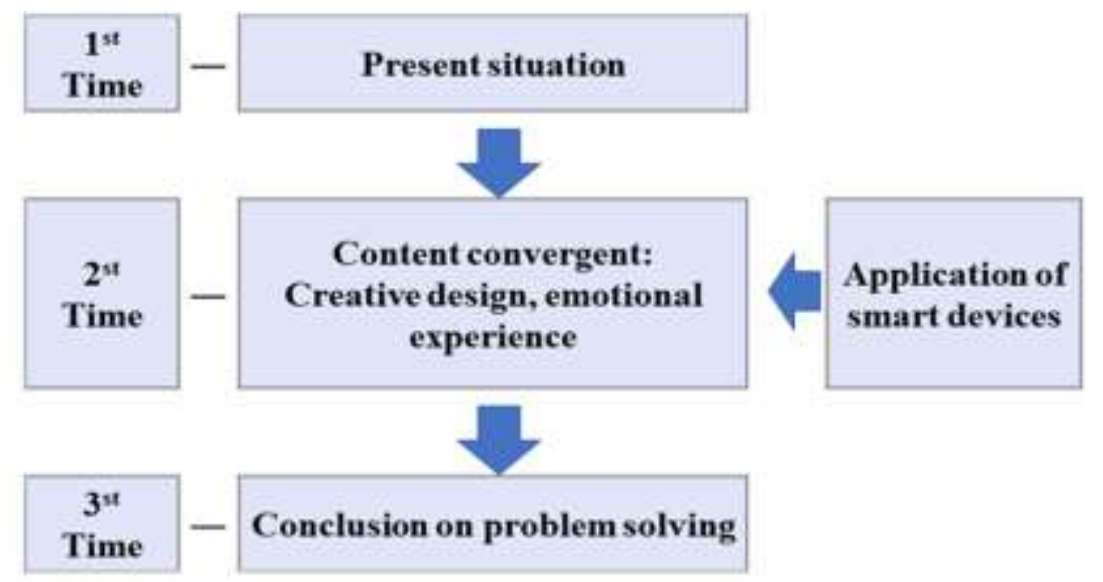

Figure 3 The STEAM teaching model based on smart device for young children

[Step 1] Situation presentation: This is the step of presenting a comprehensive situation or task to be solved that encompasses the overall learning. In this stage, the learner recognizes the activity as a selfproblem, presents the situation, recognizes the problem, presents the limitations of the design, and presents the key contents that can be challenged.

[2nd stage] Creative design: This is the stage of the creative problem-solving process in which systems, elements, and processes are devised to create what is needed within given constraints. In this stage, the definition of the problem, planning of the design, selection of ideas, and production are actually constructed.

[Step 2] Emotional experience: This is a step in which you feel interest and get motivation for new challenges through experiences of immersion and success in the process of solving problems yourself. This stage includes appropriate rewards and encouragement, such as learner's experience of success, interest in learning, sense of achievement, and confidence, and feedback from teachers.

[Step 3] Conclusion on problem solving: This is the step to draw the final conclusion on problem solving. In this stage, learners evaluate their own activities and share their findings with friends.

3.2 The STEAM program based on smart device

Table 2 shows the STEAM program applied that model based on smart device for connection of kindergarten-elementary school.

Table 2 The STEAM program based on smart device

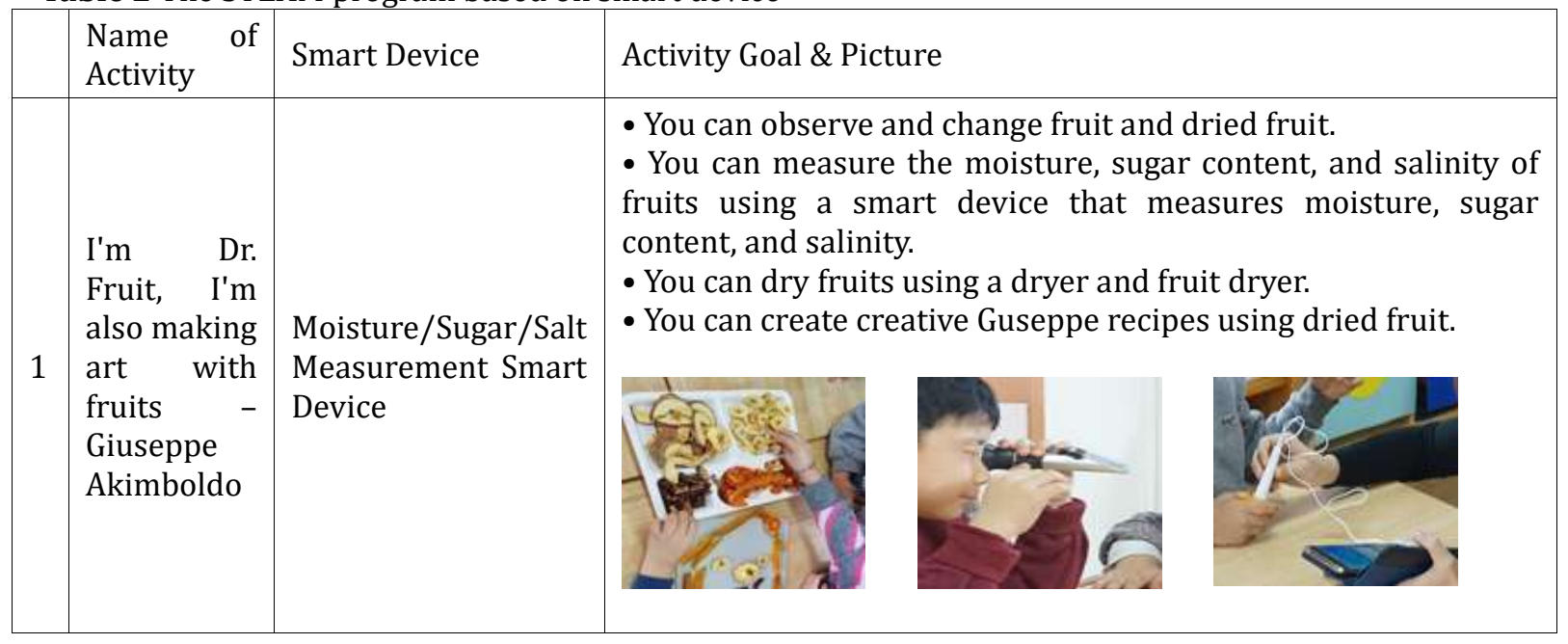




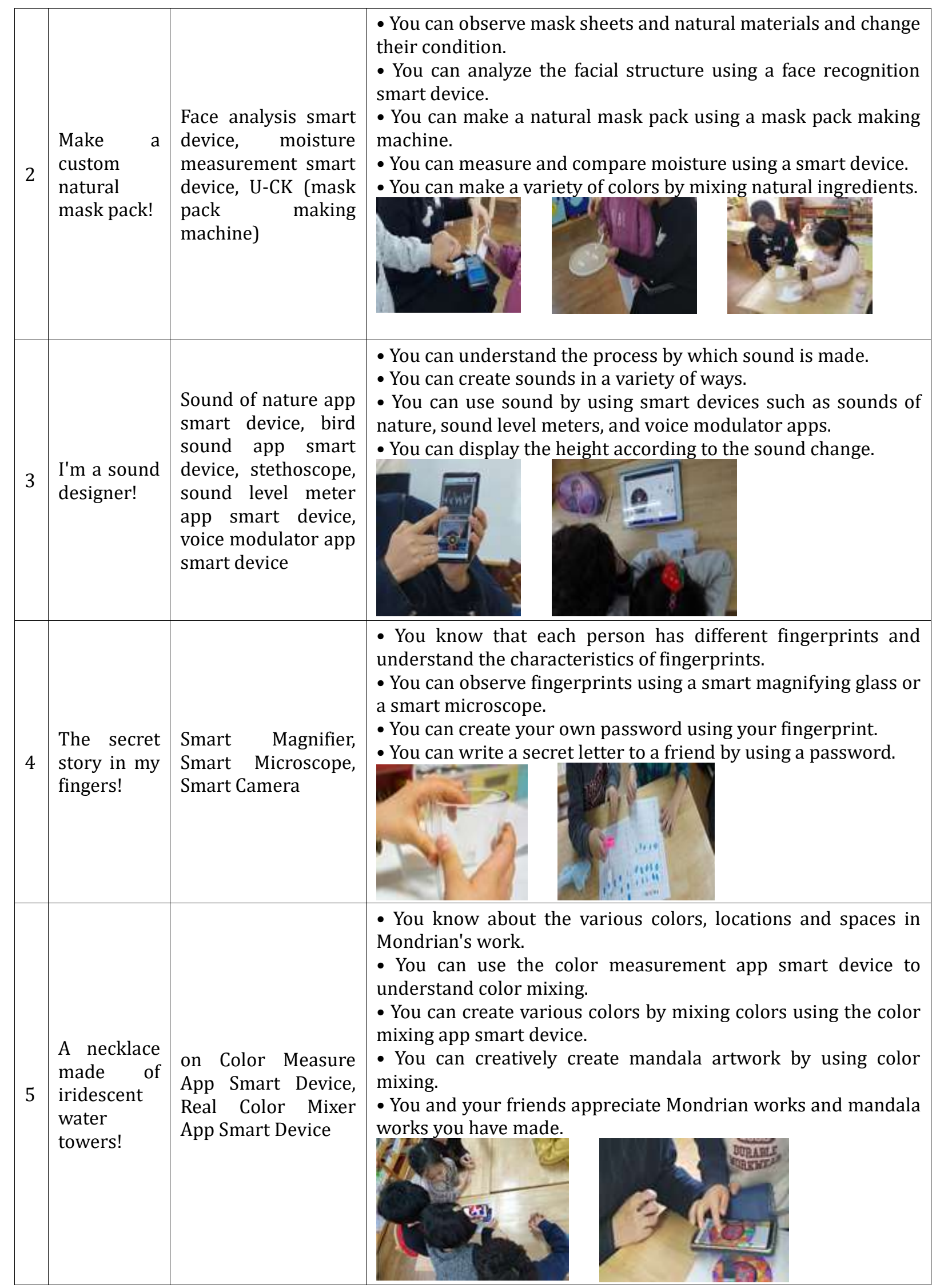




\begin{tabular}{|c|c|c|c|}
\hline 6 & $\begin{array}{l}\text { Water and } \\
\text { white } \\
\text { powder } \\
\text { meet! }\end{array}$ & $\begin{array}{l}\text { Magnifying Glass } \\
\text { Smart Device, My } \\
\text { Lab Smart Device, } \\
\text { Silent Camera Smart } \\
\text { Device, Kitchen } \\
\text { Scale/Paper Cup } \\
\text { Weighing Device } \\
\text { Smart Device }\end{array}$ & $\begin{array}{l}\text { - You can predict the results of different experiments with } \\
\text { different powders. } \\
\text { - You can express the process of change of the powder you met } \\
\text { with water through creative movements. } \\
\text { - You can measure quantities using the Kitchen Scale smart } \\
\text { device. } \\
\text { - You can use a variety of materials to complete the elastic ball. }\end{array}$ \\
\hline 7 & $\begin{array}{l}\text { My only } \\
\text { shining } \\
\text { image in } \\
\text { the world }\end{array}$ & $\begin{array}{l}\text { Face analysis smart } \\
\text { device, magnifying } \\
\text { glass smart device, } \\
\text { future face smart } \\
\text { device, Art \& Culture } \\
\text { smart device }\end{array}$ & $\begin{array}{l}\text { - You can understand that living things grow and change. } \\
\text { - You can use Art \& Culture smart devices to compare various } \\
\text { aspects of masterpieces. } \\
\text { - You can creatively design your own future shape. } \\
\text { - You can analyze masterpieces by using any smart devices. }\end{array}$ \\
\hline 8 & $\begin{array}{l}\text { My various } \\
\text { expressions } \\
\text { on my face! }\end{array}$ & $\begin{array}{lr}\text { Heart } & \text { rate } \\
\text { measurement app } \\
\text { smart device, } & \text { Facial } \\
\text { expression app } & \text { amart } \quad \text { device, } \\
\text { Emocon app } & \text { smart } \\
\text { device } & \end{array}$ & $\begin{array}{l}\text { - You understand a variety of emotions and know how to cope } \\
\text { with your emotions. } \\
\text { - You can create a variety of facial expressions using the } \\
\text { emoticon app smart device. } \\
\text { - You can creatively design facial expressions according to your } \\
\text { emotions. } \\
\text { - You can measure and compare your body changes according to } \\
\text { your emotional changes. }\end{array}$ \\
\hline
\end{tabular}

\section{Discussion}

In this study, in the early stages of the application of smart device-based STEAM education, the development of a smart device-based STEAM class model can provide implications for early childhood education. This study has high implications that a smart device-based STEAM teaching model and program were developed after applying the smart device teaching media of elementary and elementary school students. In addition, by applying this program to the field of education, it provided fusion-type academic and educational basic materials not only in the fields of early childhood education and elementary education, but also in the fields of teacher education, technical education, and computer engineering.

In addition, it will be able to contribute to activation STEAM education in the field of early childhood education in that it has developed a new teaching method using smart devices with ict technology. In particular, as in this study, through the use of various smart device teaching media, learners can maximize educational effects such as fusion thinking ability and creativity development. Young children and elementary school students voluntarily select and utilize the smart device teaching media to express their thoughts and feelings, and creatively create their own results, resulting in a positive interaction between the learner and the smart device, and the learner's self-directed Leads to a positive effect of learning.

In the early stages of the application of smart device-based STEAM education, the development of a 
smart device-based STEAM class model can provide implications for connection of kindergartenelementary school. Including the smart device teaching media applied through this study, the steam class model, the activity plan of the steam program, etc. can be directly used as educational teaching materials for pre-school teachers. In addition, the results of this study will function as a reference frame for STEAM education, indirectly, in terms of linkage education between early childhood education and elementary education.

\section{Conclusions}

The purpose of this study was to develop the STEAM teaching model and program based on smart device for connection of kindergarten-elementary school. The purpose of developing the STEAM teaching model based on smart device for young children aged 5 and 7-years was to increase their interest in and awareness of STEAM, creativity, and convergent thinking ability. The development principles and emphasis are on applying science-based convergence education that links other subjects, based on constructivist theory, and applying smart devices to emphasize technology and engineering. As for the operation method, STEAM classes were planned and executed, plans were revised and re-executed according to the STEAM class standards for connection of kindergarten-elementary school. The STEAM teaching model based on smart device for connection of kindergarten-elementary school is 3 times of present situation, creative design and emotional experience for content convergent, and conclusion on problem solving. That is, the step 1 are the course of situation presentation and creative design, step 2 is the course of emotional experience, and step 3 is the course of conclusion on problem solving.

\section{Acknowledgements}

This work was supported by the National Research Foundation of Korea Grant funded by the Korean Government (NRF-2019S1A5A8033541).

\section{References}

[1] Kim HJ, Kim BH. Development of instruction media model based on smear device for STEAM education of young children. Advanced Science Letters, 2017;23(10):10460-463.

[2] Kim HJ, Song MS, Hong SO. The effects of science education STEAM program on young children's creativity and scientific problem solving ability, The Journal of Korea Open Association for Early Childhood Education, 2016;21(1):613-40. DOI : 10.20437/KOAECE21-1-26

[3]_Cho HS, Kim MJ, Nam KW. Effects of "STEAM education focusing music and movement activity" on children's problem solving skills, creative personality, and emotional intelligence, The Korean Journal of Early Childhood Teacher Education, 2014;18(2):421-45.

[4] Ju HJ, Cho HS. The effects of a sand play based a STEAM program for young children on creativity, science process skills, and playfulness, the Korean Journal of Early Childhood Teacher Education, 2020;24(2):171-99. DOI : 10.32349/ECERR.2020.4.24.2.171

[5] Lee SB. The effect of art education in a STEAM program on young children's art disposition and creativity, Journal of Cognitive Enhancement and Intervention, 2019;10(1):25-46. DOI : 10.21197/ICEI.10.1.2

[6] Lee YS. The direction of STEAM education in Nuri curriculum, Early Childhood Education Research, 2016;34(1):327-342. DOI : 10.18023/kjece.2014.34.1.014

[7] Choi HS, Kang BH. A study on main functions of smart education and application scheme onto infantile education, Journal of the Korea Entertainment Industry Association, 2016;10(1):159-70. DOI : 10.21184/jkeia.2016.02.10.1.159.

[8] Kim HJ. A development on S-STEAM education program utilization of a machine for early childhood in Korea, Journal of Engineering and Applied Sciences, 2017;12(21): 5714-19. DOI: 10.3923/jeasci.2017.5714.5719

[9] Yoo KJ, Yoo JS, Kang JE. Meta-analysis of effects of using ICT media in education activities in early childhood education, The Journal of Open Early Childhood Education Research, 2017;22(4):309-28.

[10] Kim JH, Hong SH. Development and effect of STEAM program on environment using smart equipment in elementary science, The Journal of Environmental education, 2-15;28(3):178-92. 
